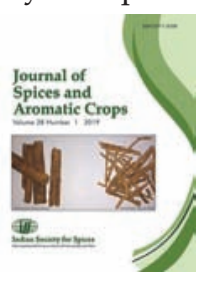

\title{
Price behaviour of black pepper in Indian and International markets: a comparative analysis
}

\author{
S S Sabu*, A Kuruvila \& K Manojkumar ${ }^{1}$ \\ Department of Agricultural Economics, \\ College of Horticulture, Vellanikkara, Thrissur-680 656, Kerala. \\ *E-mail: sachuss15@gmail.com
}

Received 03 November 2018; Revised 23 May 2019; Accepted 24 June 2019

\begin{abstract}
Black pepper, being a trade dependent commodity, shows high degree of price fluctuations. The present study examined the price behavior of black pepper in the pre-liberalisation and postliberalisation periods. The study revealed that the variation in prices increased in the postliberalisation period. Seasonal nature was evident in prices and the harvesting period was found to be coinciding with the trough phase in the price cycle, while the off-season synchronized with the peak phase. The prices exhibited cyclical behavior and the periods of low prices endured longer than that of the price spikes. The occurrence and amplitude of random factors exhibited in the prices of black pepper were more in the pre-liberalisation period.
\end{abstract}

Keywords: black pepper, domestic price, international price, pre-liberalisation, price behaviour, postliberalisation

\section{Introduction}

Agricultural commodity prices have remained considerably volatile both in India and the world over the past few decades. Commodity price volatility is a major concern for the policy makers since volatility in commodities have determined the economic prospects of nations for longer period and would continue to do so in the future (Dasgupta \& Chakrabarty 2009). The agricultural trade liberalization policies have been operating mainly through prices and it has been argued that free trade creates high volatility in the world prices of agricultural commodities (Sekhar 2004). This volatility would be directly transmitted to domestic prices due to the increased integration with the world markets, eventually leading to rise in the volatility of the Indian prices (Srinivasan \& Jha 2001). The arguments against agricultural trade liberalisation are often based on the issue of larger volatility in international markets.

Black pepper as an internationally traded commodity has always been associated with price fluctuations, which are influenced by several

${ }^{1}$ Directorate of Arecanut and Spices Development, Ministry of Agriculture \& Farmers Welfare, Govt. of India, Kozhikode-673 005, Kerala. 
factors like dynamics in domestic and international production as well as consumption, exchange rates, trade agreements and export-import policies (Sabu \& Kuruvila 2016). The prices of black pepper move cyclically through time and internationally traded black pepper shows price changes of more than five per cent from one month to another (Chopra \& Bessler 2005). Hence, the study was aimed to understand the pattern of monthly prices of black pepper in domestic and international markets during the pre-liberalisation and postliberalisation periods.

\section{Materials and methods}

The present study utilized time series data on domestic and international monthly prices of black pepper from January 1980 to December 2017 to compute the trend, seasonal, cyclical and irregular variations. The prices of black pepper in India considered for the study was that of Malabar Garbled (MG) in Cochin, whereas the international price was that of Malabar Garbled 1 (MG1) in New York. To study the influence of trade liberalization on price behaviour, the data was divided into two sub-periods viz., preliberalisation (January 1980 to December 1994) and post-liberalisation (January 1995 to December 2017) periods.

An index of instability was computed for examining the magnitude of volatility in the prices of black pepper. The co-efficient of variation $(\mathrm{CV})$ was worked out for black pepper prices in domestic as well as international market. However, simple CV does not explain properly the trend component inherent in the time series data. Alternatively, the coefficient of variation around the trend $\left(\mathrm{CV}_{\mathrm{t}}\right)$ rather than coefficient of variation around the mean $(\mathrm{CV})$ was suggested by Cuddy \& Della (1978) as a better measure of variability.

$$
\mathrm{CV}_{\mathrm{t}}=\mathrm{CV} \times \sqrt{\left(1-\bar{R}^{2}\right)}
$$

Where, $\mathrm{CV}$ is the coefficient of variation in per cent, and $\bar{R}^{2}$ is the coefficient of determination from a time trend regression adjusted for its degrees of freedom.
To analyse the time series components viz., trend, seasonal, cyclical and irregular fluctuations, a multiplicative model of the following type was used:

$Y_{t}=T_{t} C_{t} S_{t} I_{t}$

Where: $Y_{t}$ denotes the time series data on prices; $\mathrm{T}_{t}$ denotes the trend component; $\mathrm{C}_{t}$ denotes the cyclical movements; $S_{t}$ denotes the seasonal variations, and $I_{t}$ denotes the irregular variations.

\section{Analysis of long-term movements (trend)}

Trend is a general tendency of a time series data to increase or decrease over a long period. For estimating the long term trend in prices, the method of least squares and different functional forms were employed. Third order polynomial trend line was fitted to monthly prices of black pepper as it is highly fluctuating. This method of ascertaining the trend in a series of fluctuating monthly prices of black pepper involves estimating parameters in the polynomial functional form.

The equation adopted for this purpose was specified as follows:

$Y_{t}=a x^{3}+b x^{2}+c x+d$

$\mathrm{Y}_{\mathrm{t}}=$ Trend values at time ' $\mathrm{t}$ '

$a, b, c$ and $d$ are estimates of equation

Using the above equation, the trend in prices of black pepper in the selected markets were computed and compared.

\section{Estimation of seasonal indices using monthly data}

Seasonal indices were estimated using ratio to moving average method as it is less affected by upward or downward trend in prices. As the first step, a 13 months centered moving average was calculated and then seasonal indices were estimated which shows the typical intra-year movements. This may be represented by the following expression:

\section{$\frac{\mathrm{T} \times \mathrm{C} \times \mathrm{S} \times \mathrm{I}}{\mathrm{T} \times \mathrm{C} \times \mathrm{I}}=\mathrm{S}$}

$\mathrm{T}=$ Trend; C=Cyclical Component; S=Seasonal 
Component; I=Irregular Component.

\section{Estimation of cyclical indices}

The most commonly used method for estimating cyclical movement of time series is the residual method by eliminating the seasonal variation and trend. This was accomplished by dividing $\left(\mathrm{Y}_{\mathrm{t}}\right)$ by corresponding trend values and then by seasonal indices for time $(t)$, which left a residue of cyclical and irregular components.

Symbolically, $\frac{\mathrm{TCSI}}{\mathrm{S}}=\mathrm{TCI}$ and $\frac{\mathrm{TCI}}{\mathrm{T}}=\mathrm{CI}$

The irregular components were eliminated using moving average method and the index is expressed as percentage.

\section{Estimation of irregular component}

The irregular components are the "residuals" that remain in a time series after the removal of the trend, seasonal and cyclical effects. It will represent the random or irregular variations in a time series. They are the short term fluctuations, attributable to supply shocks on account of climatic deviations or demand shocks or high speculative factors. Irregular movements were obtained by dividing the cyclical versus irregular indices by the cyclical component. It was then converted into percentage terms in order to obtain the irregular index.

\section{Results and discussion}

\section{Behaviour of monthly prices of black pepper}

Black pepper is an internationally demanded commodity and hence the prices of the commodity vary substantially, from year to year, month to month and even daily prices show fluctuations. The monthly prices of black pepper in rupee in the domestic and international markets (Fig. 1) moved closely especially in the pre-liberalisation period. After 1995, there was slight divergence between the two market prices and the international price was always higher than the domestic prices. The prices of black pepper in US Dollar in the domestic and international markets (Fig. 2) showed fluctuations even before liberalization. This may be due to instability of exchange rate in pre- and post-liberalisation period (Table 1).

The magnitude of volatility of black pepper prices in rupee, has increased significantly in Indian and international markets during the postliberalisation period. Black pepper price volatility increase in Indian market in the postliberalisation period was almost two times that

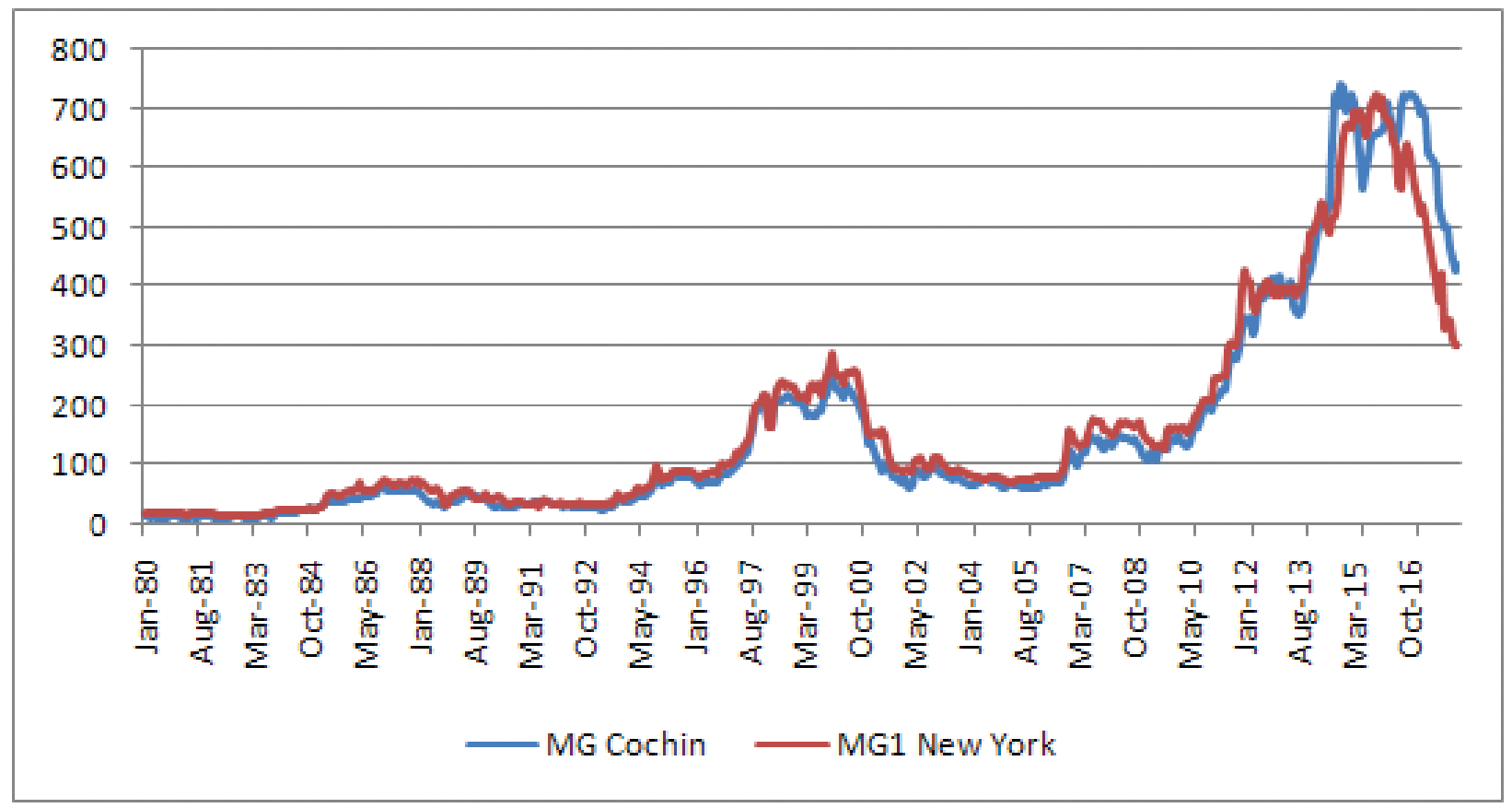

Fig. 1. Behaviour of monthly prices of black pepper (in Rupee per kilogram) 


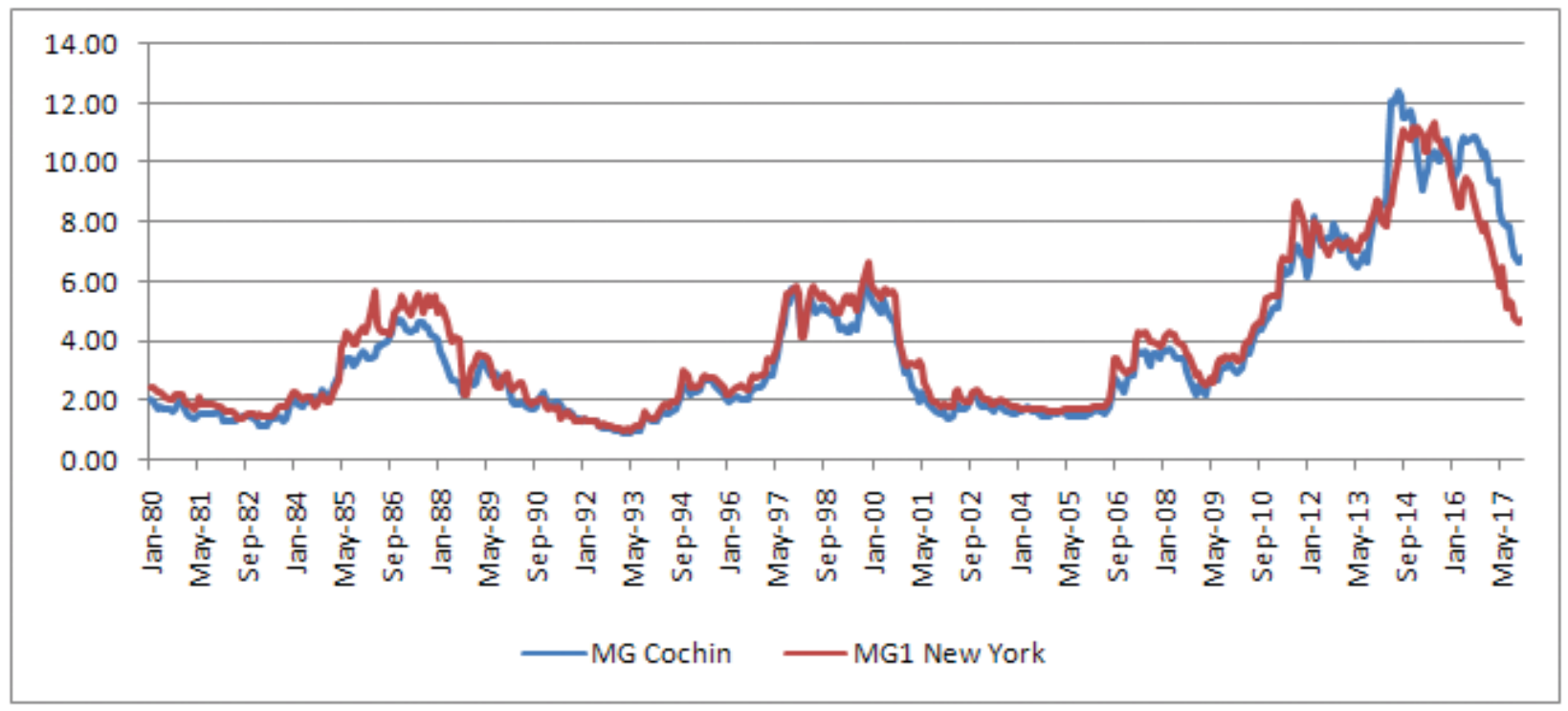

Fig. 2. Behaviour of monthly prices of black pepper (in US Dollar per kilogram)

of the volatility in the pre-liberalisation period. The volatility indices for black pepper prices in Indian market in dollar terms has also increased in the post-liberalisation whereas the international prices exhibited a fall in instability. Even though prices of black pepper were unstable in both domestic and international markets even before liberalisation, the magnitude of price instability has increased significantly in the postliberalisation period in domestic markets, whereas it declined in the international markets (Table 1).

Trend in prices indicates the general direction and change in prices over the years in different markets. A third degree polynomial equation was found to be the best fit for the monthly prices of black pepper to show the nature of trend. The results revealed that there was an increasing trend in the prices of black pepper in the domestic and international markets (Fig. 3 \& 4) and they were also found to be statistically significant.

\section{Seasonality in prices of black pepper}

As any agricultural commodity, black pepper is also seasonal in production. In Kerala, the harvesting season extends from November to January in the plains and January to March in the hills. The seasonal indices for prices of MG in Cochin market and MG 1 in New York market were estimated separately for the preliberalisation and post-liberalisation periods and are given in Table 1 . The prices of pepper exhibited considerable seasonality. The increasing phase for black pepper prices in Cochin market in the post-WTO period was observed from July to October, with the peak price in

Table 1. Instability of black pepper prices in Indian and International market (per cent)

\begin{tabular}{lcc}
\hline Market/Prices & Pre-liberalisation & Post-liberalisation \\
\hline Prices in Rupee & 35.8 & 67.3 \\
MG Cochin & 40.5 & 56.6 \\
MG 1 New York & & \\
Prices in Dollar & 48.7 & 55.4 \\
MG Cochin & 51.7 & 48.3 \\
MG 1 New York & 17.4 & 19.6 \\
Exchange rate (₹/\$) & &
\end{tabular}


Table 2. Seasonal index for black pepper prices

\begin{tabular}{lccccc}
\hline Month & \multicolumn{2}{c}{ MG Cochin } & & \multicolumn{2}{c}{ MG 1 New York } \\
\cline { 2 - 3 } \cline { 5 - 6 } January & Pre-liberalisation & Post-liberalisation & & Pre-liberalisation & Post-liberalisation \\
February & 95.54 & 96.04 & & 99.64 & 95.63 \\
March & 94.47 & 93.86 & & 100.51 & 94.44 \\
April & 95.79 & 94.49 & & 100.81 & 94.55 \\
May & 98.65 & 98.74 & & 101.46 & 98.02 \\
June & 97.64 & 99.77 & & 99.28 & 100.10 \\
July & 98.66 & 99.30 & & 99.00 & 99.35 \\
August & 100.63 & 101.15 & & 97.33 & 101.43 \\
September & 98.93 & 103.91 & & 95.74 & 102.99 \\
October & 101.36 & 103.22 & & 97.33 & 104.50 \\
November & 103.43 & 103.28 & & 98.48 & 103.45 \\
December & 104.50 & 100.32 & & 101.51 & 101.45 \\
\hline
\end{tabular}

Note: Pre-liberalisation (Jan 1980 to Dec 1994), post-liberalisation (Jan 1995 to Dec 2017)

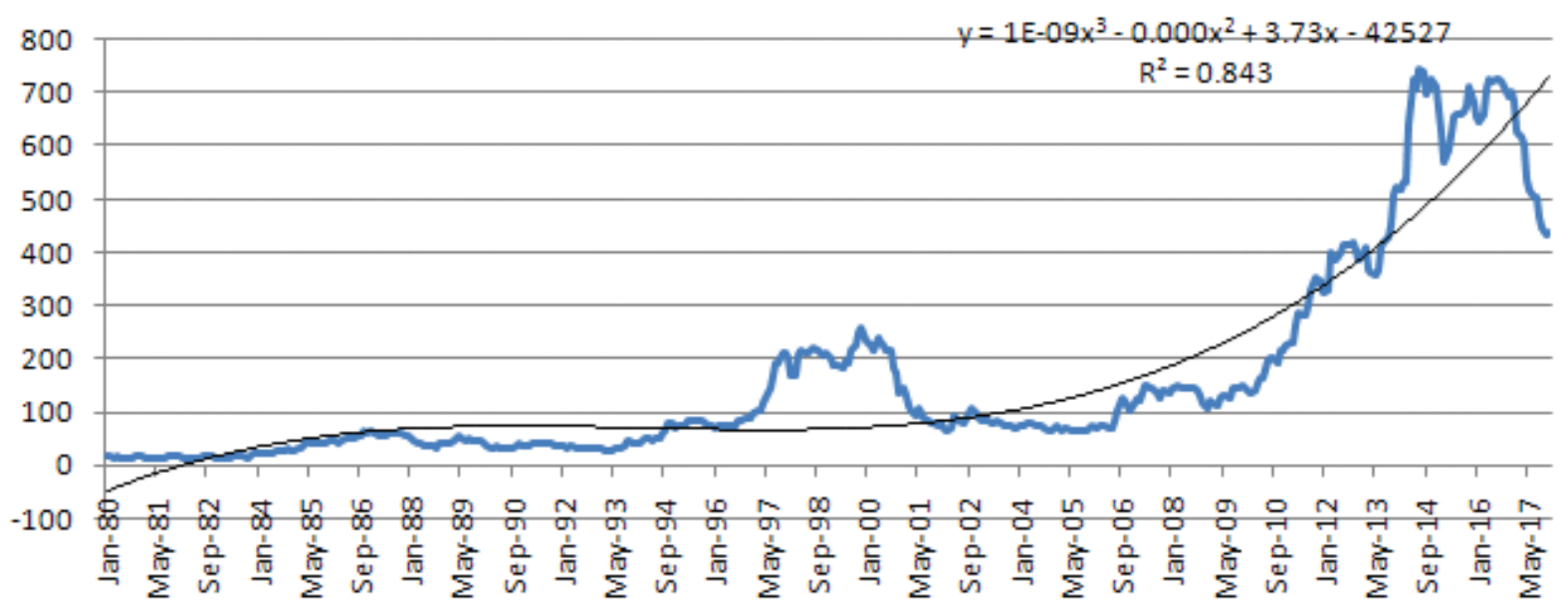

- MG Cochin Poly. (MG Cochin)

Fig. 3. Trend fitted for monthly prices of Malabar Garbled pepper in Cochin

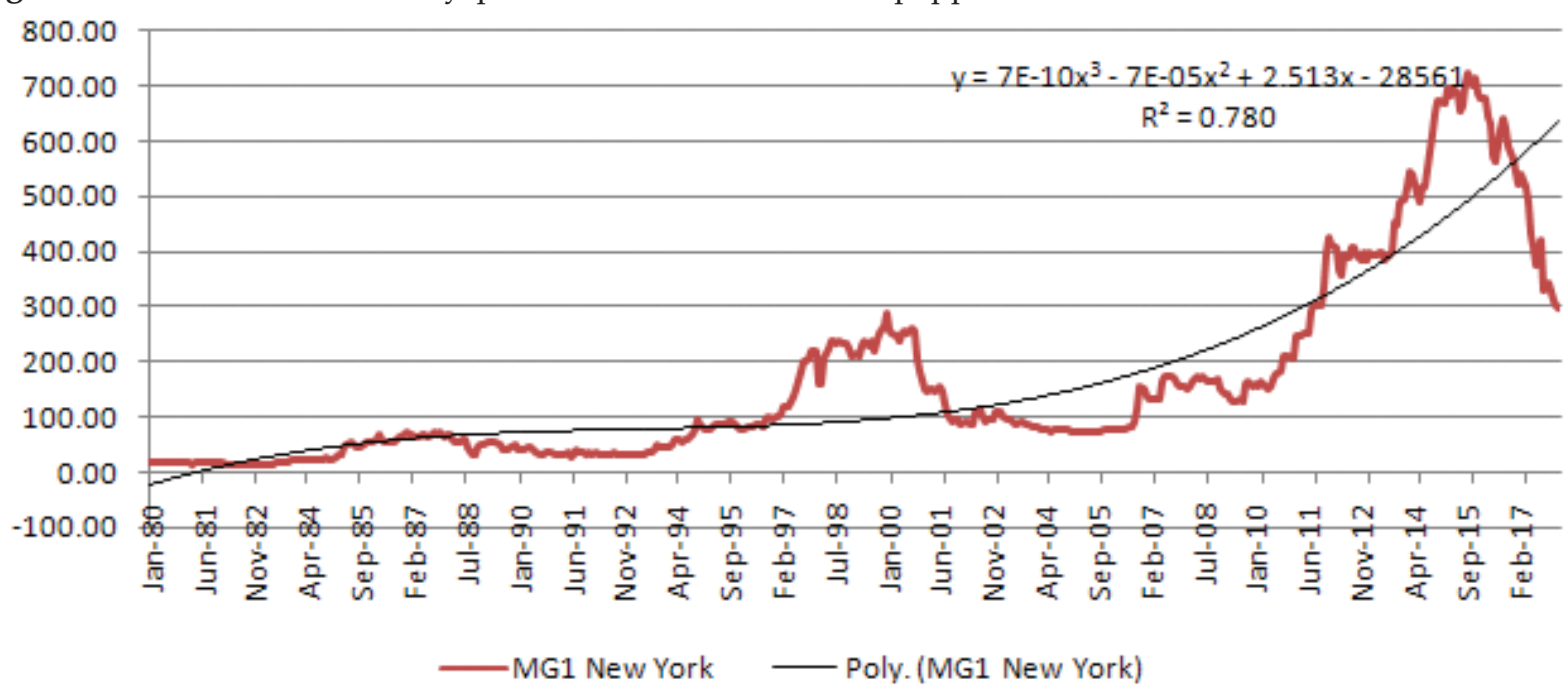

Fig. 4. Trend fitted for monthly prices of Malabar Garbled pepper in New York 
October, while for garbled pepper in New York, the highest price was observed during September. The fall in price occurs from November to February, coinciding with harvesting and consequently, the months of peak arrivals.

\section{Price cycles in black pepper}

Price cycles represent deviations in prices from the average trend due to business sequences of booms and recession that appear in an economy. Cyclical movements are of longer duration, usually extending to few years and are of different periodicity. The cyclical pattern of black pepper prices in Cochin and New York markets could be observed in Fig. 5, which moved in similar pattern. The first 11 year cycle was from 1983 to 1993 and the second cycle from 1993, showed some fluctuation near the peak values and reached the lowest value in 2005 (Rs. 60.9 in July 2005 for MG in Cochin and Rs. 70 in Feb 2005 for MG 1 in New York). The third cycle started from 2005 when the prices started increasing, reached the peak value of prices, Rs 742 in July 2014 for Malabar Garbled pepper in Cochin and Rs. 722 in July 2015 for Malabar Garbled pepper in New York and then has shown a declining pattern. The third cycle has shown an expansion in duration in the boom phase to almost nine years and now the slump phase of the cycle for last 3 years. The characteristic behaviour of cycles is that periods of low prices endure for longer than price hikes.

\section{Random price movements}

Irregular variations are the random, erratic and unpredictable components in a time series data as a result of uncontrollable as well as unforeseen situations, mainly weather related problems and unpredictable policy actions. The indices of irregular variations have been worked out to capture the random effect (Fig. 6) and it was found that the prices of black pepper were subjected to considerable fluctuations over time. The occurrence and amplitude of random factors exhibited in the prices of black pepper were more in pre-liberalisation period, indicating that random factors caused more fluctuations in preliberatisation period than the post-liberalisation period.

The study revealed that in the long run, domestic and international markets showed an increasing trend in the prices of black pepper over the years. The price fluctuations of black pepper in domestic and international markets were quite high and the variation in prices has generally increased in the post-liberalisation period. Black pepper prices were subjected to a pronounced seasonality and the harvest period was coupled with a trough phase, while the off-season synchronized with a buoyant phase. Even though prices of black pepper were unstable in both domestic and international markets even before liberalisation, the price volatility has increased significantly in the post-liberalisation period. This could be attributed to the fact that with increased openness of India to international trade as a result of trade liberalisation policies, the high volatility in international markets were getting transmitted to domestic markets.

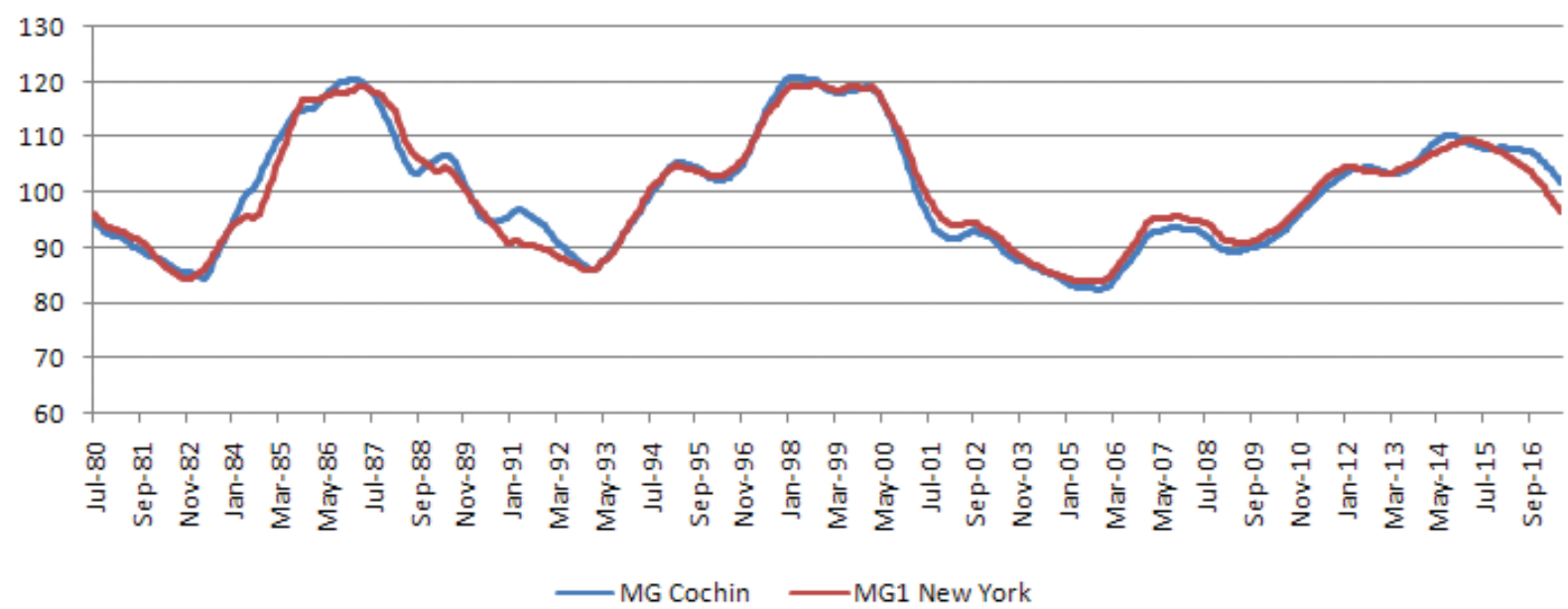

Fig. 5. Cyclical indices for prices of Malabar Garbled pepper in Cochin and New York markets 


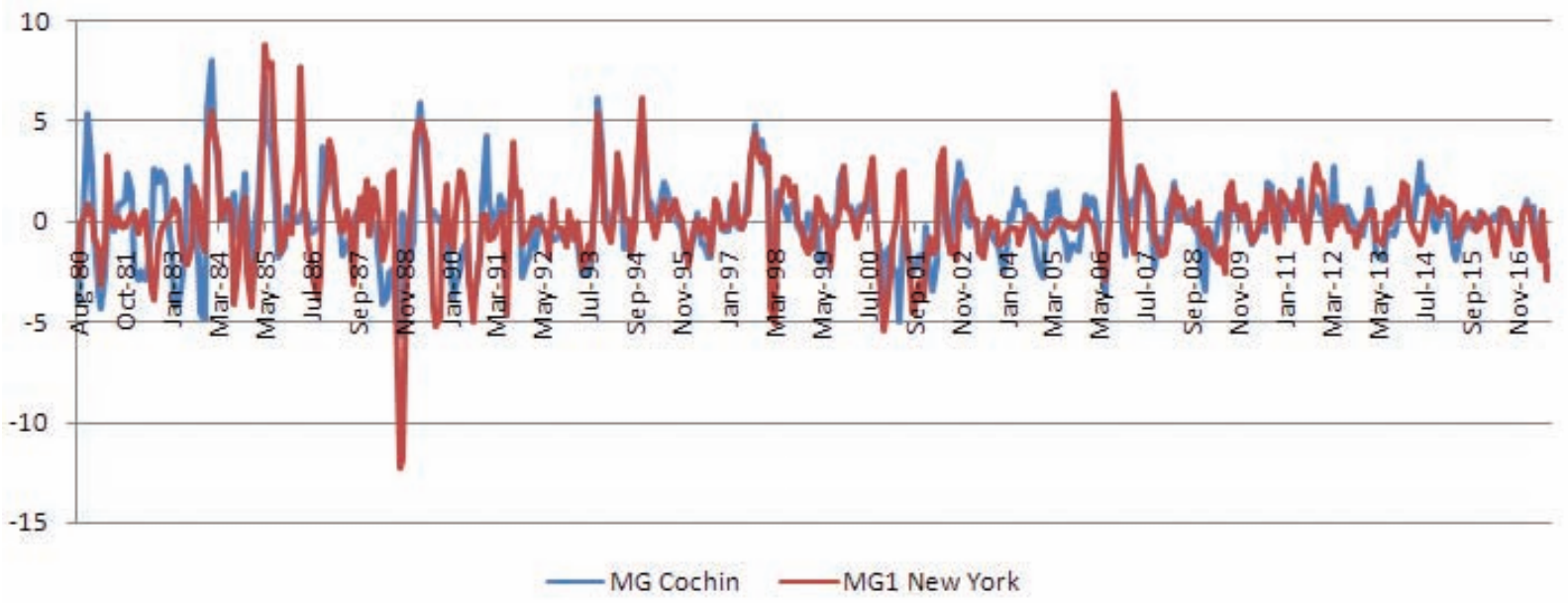

Fig. 6. Irregular variation in the monthly prices of Malabar Garbled pepper in Cochin and New York markets

As black pepper prices are subjected to high volatility, institutional mechanisms are needed to protect farmers providing adequate and timely information regarding the black pepper prices through market intelligence. Proper implementation of the warehouse receipt system enable the farmers to borrow from banks using the warehouse receipt as collateral. This will help the farmers to meet their immediate cash needs and reduce the vulnerability of farmers to price volatility by preventing distress sales. The benefits of future trading with regard to coverage of price risk should be extended to small and marginal farmers by ensuring their participation. Actual delivery of the commodity should also be made obligatory so as to prevent illegitimate speculation and the resultant volatility transmission from futures to spot markets.

\section{Acknowledgement}

We express our sincere gratitude to Kerala Agricultural University for providing the facilities. And also Directorate of Arecanut and Spices Development, Kozhikode, and Spices Board, Kochi for the support during secondary data collection.

\section{References}

Chopra A \& Bessler D A 2005 Price discovery in the black pepper market in Kerala, India. Indian Econ. Rev. 40: 1-21.

Cuddy J D A \& Valle P A D 1978 Measuring the instability of time series data. Oxford Bull. Econ. Statist. 40: 53-78.

Dasgupta K \& Chakrabarty C 2009 Commodities Derivative Hedging: Portfolio and Effectiveness. Commodity Insights Yearbook, Multi Commodity Exchange of India Limited, Mumbai. pp.53-59.

Sabu S S \& Kuruvila A 2016 Price instability in black pepper: a comparative analysis of preliberalisation and post-liberalisation periods. J. Trop. Agri. 54: 41-49.

Sekhar C S C 2004 Agricultural price volatility in international and Indian markets. Econ. Polit. Wkly. 39: 4729-4736.

Srinivasan P V \& Jha S 2001 Food grain price stabilization: Implications of private storage and subsidised food distribution. J. Poli. Model. 19: 587-60. 